\title{
JEKK
}

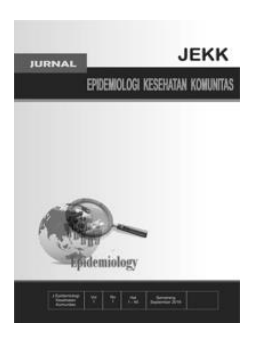

\section{Faktor-Faktor yang Berhubungan dengan Ketepatan Waktu Vaksinasi Meningitis pada Jamaah Umrah (Studi di Kota Bengkulu)}

\author{
Ernawati $^{*}$, Ari Udiyono ${ }^{* *}$, Martini Martini ${ }^{* * *}$, Lintang Dian Saraswati ${ }^{* * * *}$ \\ "Kantor Kesehatan Pelabuhan Bengkulu, ${ }^{* *}$ Fakultas Kesehatan Masyarakat, Universitas Diponegoro
}

\begin{abstract}
Background: Meningococcal meningitis is a disease with high morbidity and mortality which, if left untreated, $100 \%$ will end in death. Meningitis vaccination is a way to prevent transmission of meningitis in high-risk groups such as Umrah pilgrims. As many as $26.69 \%$ of Umrah pilgrims in Bengkulu were late in conducting the meningitis vaccination.

Methods: Used is analytic observational research with cross sectional approach. The research sample of 122 people with purposive sampling. Data processing was performed by chi square test by looking at the value of continuity correction and pearson chi-square with $\alpha=0.05$.

Result: There is a significant relationship between the level of knowledge about the time of meningitis vaccination, $(p=0,000)$ and the perseption of role of umrah travel agency $(p=0,023)$ with the timeliness of vaccination. There was no relationship between age $(p=0,328)$, sex $(p=0,998)$, level of education $(p=0,868)$, type of work $(p=1,000)$, level of knowledge about meningitis $(p=0,477)$, level of knowledge about vaccination meningitis $(p=0,903)$, family support $(p=0,083)$ and distance access to health services $(p=0,996)$ with timely meningitis vaccination in Umrah pilgrims.

Conclusion : Knowledge about the timing of vaccination and the perseption of role of umrah travel agency are the main determining factors of the accuracy of meningitis vaccination in Umrah pilgrims.
\end{abstract}

Keywords: Meningitis vaccination; umrah pilgrims; timeliness vaccination.

*Penulis korespondensi, ernawatiheriansyah@gmail.com 


\section{Pendahuluan}

Meningitis meningokokus merupakan penyakit dengan morbiditas dan mortalitas tinggi. Meningitis meningokokus merupakan salah satu kasus gawat darurat yang ditandai dengan proses inflamasi pada lapisan meningen sebagai reaksi infeksi bakteri. Bila tidak ditangani, $100 \%$ akan berakhir dengan kematian; meskipun telah diterapi dengan antibiotik dan penanganan intensif, 5-10\% kasus dapat berakhir dengan kematian. $N$. meningiditis merupakan penyebab utama meningitis di negara berkembang, diperkirakan terdapat 500.000 kasus setiap tahunnya, 50.000 diantaranya menyebabkan kematian; insidens tertinggi terjadi di daerah Sub Sahara Afrika yang disebut sebagai sabuk meningitis. Epidemi terjadi selama musim panas dengan insidens tahunan sebanyak 1.000-1.200 kasus, dan berkaitan dengan kunjungan haji atau umrah tahunan. ${ }^{1}$

Pemberian imunisasi meningitis pada jamaah haji dan umrah merupakan metode yang efektif dalam mengurangi angka kesakitan serta kematian akibat penyakit meningitis. ${ }^{2,3}$ untuk membentuk kekebalan yang optimal, ${ }^{4}$ vaksinas meningitis sebaiknya diberikan minimal 30 (tiga puluh) hari sebelum keberangkatan. ${ }^{5}$ Dari data SIMKESPEL KKP Bengkulu tahun 2018, didapatkan sebanyak 924 orang $(26,69 \%)$ jamaah melakukan vaksinasi kurang dari 30 hari.

Berbagai faktor mempengaruhi perilaku seseorang dalam mendapatkan penyuntikan vaksinasi seperti faktor demografi (usia, jenis kelamin, tingkat pendidikan, status pekerjaan), rekomendasi agen pemerintahan, kepercayaan/ keyakinan, ${ }^{6}$ tingkat pengetahuan, sikap, persepsi kerentanan, persepsi manfaat, dukungan lingkungan dan keterjangkaun pelayanan kesehatan. ${ }^{6-9}$

Dengan diketahuinya faktor yang berhubungan dengan ketepatan waktu vaksinasi meningitis pada jamaah umrah maka intervensi oleh pihak terkaitpun akan lebih tepat sasaran, hal ini merupakan tujuan dari penelitian ini.

\section{Metode}

Penelitian ini merupakan penelitian observasional analitik dengan pendekatan desain Cross Sectional. Teknik pengambilan sampel dengan Purposive sampling dengan jumlah sampel sebesar 122 responden yang telah memenuhi kriteria inklusi dan eklusi yang telah ditetapkan. Instrumen yang digunakan adalah kuisioner. Analisis data univariat dengan tabel distribusi frekuensi pada masingmasing variabel dan analisa data bivariat untuk menganalisis hubungan antara variabel bebas dengan variabel terikat menggunakan uji chi square dengan melihat nilai signifikansi pada kolom continuity correction dan pearson chisquare dengan $\alpha=0,05$.

\section{Hasil}

\section{Analisis univariat}

Responden sebagian besar berada pada kelompok usia 30-60 tahun sebanyak $(71,3 \%)$, jenis kelamin sebagian besar responden adalah perempuan $(59,8 \%)$, berpendidikan terakhir mayoritas pendidikan tinggi $(49,2 \%)$, mayoritas responden bekerja $(67,2 \%)$, melakukan vaksinasi tidak tepat waktu $(54,1 \%)$, memiliki pengetahuan tentang penyakit meningitis yang cukup (50,8\%), memiliki pengetahuan tentang vaksinasi meningitis yang cukup $(53,3 \%)$, memilik tingkat pengetahuan tentang waktu vaksinasi yang kurang (70,5\%), memiliki dukungan keluarga yang cukup (54,9\%), memiliki akses jarajk tempuh yang jauh ke pelayanan kesehatan $(90,2 \%)$, memiliki waktu tempuh ke tempat pelayanan kesehatan yang dekat $(60,7 \%)$, memiliki persepsi terhadap peran PPIU yang baik $(67,2 \%)$.

Tabel 1. Distribusi Frekuensi Variabel Penelitian

\begin{tabular}{llcc}
\hline No $\quad$ Variabel & f & $\%$ \\
\hline 1. & Usia & & \\
& <30 Th \& $>60 \mathrm{Th}$ & 35 & 28,7 \\
& 30-60 Th & 87 & 71,3 \\
2. Jenis Kelamin & & \\
& Laki-laki & 49 & 40,2 \\
& Perempuan & 73 & 59,8 \\
\hline
\end{tabular}




\begin{tabular}{|c|c|c|c|}
\hline No & Variabel & f & $\%$ \\
\hline \multirow[t]{4}{*}{3.} & Tingkat Pendidikan & & \\
\hline & Pendidikan Dasar & 30 & 24,6 \\
\hline & Pendidikan Menengah & 32 & 26,2 \\
\hline & Pendidikan Tinggi & 60 & 49,2 \\
\hline \multirow[t]{3}{*}{4.} & Jenis pekerjaan & & \\
\hline & Bekerja & 82 & 67,2 \\
\hline & Tidak bekerja & 40 & 32,8 \\
\hline \multirow[t]{3}{*}{5.} & Ketepatan waktu vaksinasi & & \\
\hline & Tidak tepat waktu(<30 hari) & 66 & 54,1 \\
\hline & Tepat waktu( $\geq 30$ hari $)$ & 56 & 45,9 \\
\hline \multirow[t]{3}{*}{6.} & $\begin{array}{l}\text { Pengetahuan tentang penyakit } \\
\text { meningitis }\end{array}$ & & \\
\hline & Kurang & 60 & 49,2 \\
\hline & Cukup & 62 & 50,8 \\
\hline \multirow[t]{3}{*}{7.} & $\begin{array}{l}\text { Pengetahuan tentang vaksinasi } \\
\text { meningitis }\end{array}$ & & \\
\hline & Cukup & 57 & 46,7 \\
\hline & Kurang & 65 & 53,3 \\
\hline \multirow[t]{3}{*}{8.} & $\begin{array}{l}\text { Pengetahuan tentang waktu } \\
\text { vaksinasi meningitis }\end{array}$ & & \\
\hline & Tidak tahu & 84 & 70,0 \\
\hline & Tahu & 36 & 30,0 \\
\hline \multirow[t]{3}{*}{9.} & Dukungan Keluarga & & \\
\hline & Cukup & 53 & 44,2 \\
\hline & Kurang & 67 & 55,8 \\
\hline \multirow[t]{6}{*}{10.} & $\begin{array}{l}\text { Akses ke Yankes } \\
\text { - Jarak tempuh }\end{array}$ & & \\
\hline & Jauh & 110 & 90,2 \\
\hline & Dekat & 12 & 9,8 \\
\hline & - Waktu tempuh & & \\
\hline & Sangat Dekat & 48 & 39,3 \\
\hline & Dekat & 74 & 60,7 \\
\hline \multirow[t]{3}{*}{11.} & Persepsi terhadap peran PPIU & & \\
\hline & Kurang baik & 40 & 32,8 \\
\hline & Baik & 82 & 67,2 \\
\hline
\end{tabular}

\section{Analisis bivariat}

Tabel 2. Hubungan Usia dengan Ketepatan Waktu Vaksinasi Meningitis

\begin{tabular}{|c|c|c|c|c|c|c|c|}
\hline \multirow[t]{3}{*}{ Usia } & \multicolumn{4}{|c|}{$\begin{array}{c}\text { Ketepatan waktu } \\
\text { vaksinasi }\end{array}$} & \multirow{2}{*}{\multicolumn{2}{|c|}{ Total }} & \multirow[t]{3}{*}{$\mathrm{P}$} \\
\hline & \multicolumn{2}{|c|}{$\begin{array}{l}\text { Tidak tepat } \\
\text { waktu }\end{array}$} & \multicolumn{2}{|c|}{$\begin{array}{l}\text { Tepat } \\
\text { waktu }\end{array}$} & & & \\
\hline & $\mathrm{f}$ & $\%$ & $\mathrm{f}$ & $\%$ & $f$ & $\%$ & \\
\hline$<30 \&>60$ & 16 & 45,7 & 19 & 54,3 & 35 & 100,0 & 0,328 \\
\hline $30-60$ & 50 & 57,5 & 37 & 42,5 & 87 & 100,0 & \\
\hline
\end{tabular}

Tabel 3. Hubungan Jenis Kelamin dengan Ketepatan Waktu Vaksinasi Meningitis

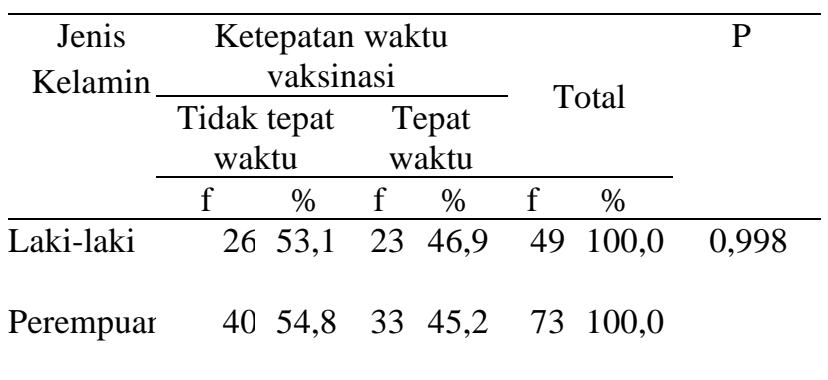

Tabel 4. Hubungan Tingkat Pendidikan dengan Ketepatan Waktu Vaksinasi Meningitis

\begin{tabular}{|c|c|c|c|c|c|c|}
\hline \multirow[t]{3}{*}{$\begin{array}{c}\text { Tingkat } \\
\text { Pendidikan }\end{array}$} & \multicolumn{4}{|c|}{$\begin{array}{l}\text { Ketepatan waktu } \\
\text { vaksinasi }\end{array}$} & \multirow[b]{2}{*}{ Total } & \multirow[t]{3}{*}{$\mathrm{P}$} \\
\hline & \multicolumn{2}{|c|}{$\begin{array}{c}\text { Tidak } \\
\text { tepat } \\
\text { waktu }\end{array}$} & \multicolumn{2}{|c|}{$\begin{array}{l}\text { Tepat } \\
\text { waktu }\end{array}$} & & \\
\hline & $\mathrm{f}$ & $\%$ & $f$ & $\%$ & f $\%$ & \\
\hline Dasar & 17 & 56,7 & 13 & 43,3 & 30100,0 & 0,868 \\
\hline Menengah & 18 & 56,3 & 14 & 43,8 & 32100,0 & \\
\hline Tinggi & 31 & 51,7 & 29 & 48,3 & 60100,0 & \\
\hline
\end{tabular}

Tabel 5. Hubungan Jenis Pekerjaan dengan Ketepatan Waktu Vaksinasi Meningitis

\begin{tabular}{|c|c|c|c|c|c|c|c|}
\hline \multirow[t]{3}{*}{$\begin{array}{c}\text { Jenis } \\
\text { pekerjaan }\end{array}$} & \multicolumn{4}{|c|}{$\begin{array}{c}\text { Ketepatan waktu } \\
\text { vaksinasi }\end{array}$} & \multirow{2}{*}{\multicolumn{2}{|c|}{ Total }} & \multirow[t]{3}{*}{$P$} \\
\hline & \multicolumn{2}{|c|}{$\begin{array}{l}\text { Tidak tepat } \\
\text { waktu }\end{array}$} & \multicolumn{2}{|c|}{$\begin{array}{l}\text { Tepat } \\
\text { waktu }\end{array}$} & & & \\
\hline & $\mathrm{f}$ & $\%$ & $\mathrm{f}$ & $\%$ & $\mathrm{f}$ & $\%$ & \\
\hline Bekerja & 44 & 53,7 & 38 & 46,3 & 82 & 100,0 & 1,000 \\
\hline $\begin{array}{l}\text { Tidak } \\
\text { Bekerja }\end{array}$ & 22 & 55,0 & 18 & 45,0 & 40 & 100,0 & \\
\hline
\end{tabular}

Tidak terdapat hubungan yang signifikan antara umur $(p=0,328)$, jenis kelamin $(p=0,998)$, Tingkat pendidkan $(p=0,868)$ dan jenis pekerjaan $(p=1,000)$ dengan ketepatan waktu vaksinasi (tabel 2,3,4,5). 
Berdasarkan tabel 6 diketahui bahwa terdapat hubungan yang signifikan antara tingkat pengetahuan tentang waktu vaksinasi meningitis $(p=0,000)$ dengan ketepatan wakitu vaksinasi meningitis sementara tidak terdapat hubungan yang signifikan antara tingkat pengetahuan tentang penyakit meningitis $(p=0,477)$ dan tingkat pengetahuan tentang vaksinasi meningitis $(p=0,903)$ dengan ketepatan waktu vaksinasi meningitis pada jamaah umrah.

Tabel 6. Hubungan Tingkat Pengetahuan dengan Ketepatan Waktu Vaksinasi Meningitis

\begin{tabular}{|c|c|c|c|}
\hline $\begin{array}{l}\text { Tingkat } \\
\text { pengetahu }\end{array}$ & $\begin{array}{l}\text { Ketepatan w } \\
\text { vaksinasi }\end{array}$ & ktu & \\
\hline an & $\begin{array}{c}\text { Tidak tepat } \\
\text { waktu }\end{array}$ & $\begin{array}{l}\text { Tepat } \\
\text { waktu }\end{array}$ & Total \\
\hline & $\%$ & $\%$ & $\%$ \\
\hline
\end{tabular}

Penyakit

Meningitis

$\begin{array}{llllllll}\text { Kurang } & 30 & 50,0 & 30 & 50,0 & 60 & 100,0 & 0,477 \\ \text { Cukup } & 36 & 58,1 & 26 & 41,9 & 62 & 100,0\end{array}$

\begin{tabular}{llllllll}
\hline Vaksinasi & & & & & & \\
Meningitis & & & & & & \\
Kurang & 30 & 52,6 & 27 & 47,4 & 57 & 100,0 & 0,903 \\
Cukup & 36 & 55,4 & 29 & 44,6 & 65 & 100,0 &
\end{tabular}

\section{Waktu}

vaksinasi

meningitis

Tidak tahu

$61 \quad 70,9 \quad 25 \quad 29,1 \quad 86 \quad 100,0 \quad 0,000$

Tahu

$$
\begin{array}{llllll}
5 & 13,9 & 31 & 86,1 & 36 & 100,0
\end{array}
$$

Tabel 7. Hubungan Dukungan Keluarga dengan Ketepatan Waktu Vaksinasi Meningitis

\begin{tabular}{|c|c|c|c|c|c|c|}
\hline \multirow[t]{3}{*}{$\begin{array}{c}\text { Dukungan } \\
\text { Keluarga }\end{array}$} & \multicolumn{3}{|c|}{$\begin{array}{c}\text { Ketepatan waktu } \\
\text { vaksinasi }\end{array}$} & \multirow{2}{*}{\multicolumn{2}{|c|}{ Total }} & \multirow[t]{3}{*}{$\mathrm{P}$} \\
\hline & $\begin{array}{l}\text { Tidak tepat } \\
\text { waktu }\end{array}$ & \multicolumn{2}{|c|}{$\begin{array}{l}\text { Tepat } \\
\text { waktu }\end{array}$} & & & \\
\hline & $\mathrm{f} \quad \%$ & $\mathrm{f}$ & $\%$ & $\mathrm{f}$ & $\%$ & \\
\hline Kurang & 3563,6 & 20 & 36,4 & 55 & 100,0 & 0,083 \\
\hline Cukup & 3146,3 & 36 & 53,7 & 67 & 100,0 & \\
\hline
\end{tabular}

Tabel 8. Hubungan Akses Jarak dengan Ketepatan Waktu Vaksinasi Meningitis

\begin{tabular}{|c|c|c|c|c|c|c|c|}
\hline \multirow{3}{*}{$\begin{array}{c}\text { Akses } \\
\text { jarak } \\
\text { tempuh }\end{array}$} & \multicolumn{4}{|c|}{$\begin{array}{c}\text { Ketepatan waktu } \\
\text { vaksinasi }\end{array}$} & \multirow{2}{*}{\multicolumn{2}{|c|}{ Total }} & \multirow[t]{3}{*}{$\mathrm{P}$} \\
\hline & \multicolumn{2}{|c|}{$\begin{array}{l}\text { Tidak tepat } \\
\text { waktu }\end{array}$} & \multicolumn{2}{|c|}{$\begin{array}{r}\text { Tepat } \\
\text { waktu }\end{array}$} & & & \\
\hline & $\mathrm{f}$ & $\%$ & $\mathrm{f}$ & $\%$ & $\mathrm{f}$ & $\%$ & \\
\hline Jauh & 59 & 53,6 & 51 & 46,4 & 110 & 100,0 & 0,996 \\
\hline Dekat & & 58,3 & 5 & 41,7 & 12 & 100,0 & \\
\hline
\end{tabular}

Tabel 9. Hubungan Persepsi terhadap Peran Penyelenggara Perjalanan Ibadah Umrah (PPIU) dengan Ketepatan Waktu Vaksinasi Meningitis

\begin{tabular}{|c|c|c|c|c|c|c|c|}
\hline \multirow[t]{3}{*}{$\begin{array}{l}\text { Peran } \\
\text { PPIU }\end{array}$} & \multicolumn{4}{|c|}{$\begin{array}{c}\text { Ketepatan waktu } \\
\text { vaksinasi }\end{array}$} & \multirow{2}{*}{\multicolumn{2}{|c|}{ Total }} & \multirow[t]{3}{*}{$\mathrm{P}$} \\
\hline & \multicolumn{2}{|c|}{$\begin{array}{c}\text { Tidak tepat } \\
\text { waktu }\end{array}$} & \multicolumn{2}{|c|}{$\begin{array}{r}\text { Tepat } \\
\text { waktu }\end{array}$} & & & \\
\hline & $\mathrm{f}$ & $\%$ & $\mathrm{f}$ & $\%$ & $\mathrm{f}$ & $\%$ & \\
\hline $\begin{array}{l}\text { Kurang } \\
\text { baik }\end{array}$ & 28 & 70,0 & 12 & 30,0 & 40 & 100,0 & 0,023 \\
\hline Baik & 38 & 46,3 & 44 & 53,7 & 82 & 100,0 & \\
\hline
\end{tabular}

Tidak terdapat hubungan yang signifikan antara dukungan keluarga $(p=0,083)$, akses jarak tempuh ke pelayanan kesehatan $(p=0,996)$ dengan ketepatan waktu vaksinasi (tabel 7,8) sementara terdapat hubungan yang signifikan antara persepsi terhadap peran PPIU $(p=0,023)$ dengan ketepatan waktu vaksinasi meningitis pada jamaah umrah. (tabel 9).

\section{Pembahasan}

Umur, jenis kelamin, tingkat pendidikan dan jenis pekerjaan tidak berhubungan dengan ketepatan waktu vaksinasi

Usia memberikan informasi mengenai status perkembangan individu. ${ }^{10}$ Usia juga merupakan karakteristik yang dimiliki jamaah umrah yang membedakan tingkat kedewasaan jamaah umrah. Makin tua usia seseorang maka proses perkembangan mentalnya bertambah baik, akan tetapi pada usia tertentu, bertambahnya proses perkembangan mental ini tidak secepat seperti saat berusia belasan tahun. Selain itu, usia juga akan mempengaruhi daya ingat seseorang. ${ }^{11}$ Hasil penelitian menunjukkan bahwa usia tidak berhubungan dengan ketepatan waktu vaksinasi. Hal ini 
sejalan dengan penelitian Hafsoh SO yang menunjukkan bahwa bahwa usia tidak berhubungan dengan penerimaan vaksin meningitis pada jamaah umrah $(p=0,188){ }^{7}$ Tidak adanya hubungan ini dikarenakan Menurut Rosenstock et al (1998), usia merupakan salah satu faktor demografi yang tidak berhubungan langsung dengan kepatuhan melainkan berhubungan langsung dengan persepsi seseorang terhadap suatu tindakan pencegahan penyakit dan persepsi itulah yang berhubungan langsung dengan perilaku kepatuhan seseorang. ${ }^{12}$

Hasil penelitian menunjukkan tidak ada hubungan jenis kelamin dengan ketepatan waktu vaksinasi jamaah. Hal ini sejalan dengan penelitian di Amerika Serikat. ${ }^{13}$ Tidak adanya hubungan yang signifikan antara jenis kelamin dengan ketepatan waktu vaksinasi meningitis disebabkan karena jenis kelamin bukan merupakan faktor yang berhubungan langsung dengan kepatuhan melainkan berhubungan langsung dengan persepsi dan persepsi itulah yang berhubungan langsung dengan kepatuhan, dengan kata lain jenis kelamin akan mempengaruhi perubahan mental penderita untuk memutuskan melakukan tindakan pencegahan penyakit seperti vaksinasi. ${ }^{14}$

Pendidikan dapat memperluas wawasan atau pengetahuan seseorang. Secara umum seseorang yang berpendidikan lebih tinggi akan mempunyai pengetahuan yang lebih luas dibandingkan dengan seseorang yang tingkat pendidikannya lebih rendah. ${ }^{11}$ Tingkat pendidikan dari individu mempengaruhi penerimaan individu terhadap informasi kesehatan. $^{10}$ Hasil penelitian menunjukkan tidak ada hubungan yang signifikan antara tingkat pendidikan jamaah dengan ketepatan waktu vaksinasi meningitis pada jamaah umrah sejalan dengan penelitian Egici MT yang menyebutkan bahwa status pendidikan seseorang tidak berhubungan dengan status vaksinasi pada orang dewasa dengan hasil $p>0,05 .{ }^{15}$ Pendidikan responden adalah pendidikan yang didapat dari jalur formal. Akan tetapi tingkat pendidikan formal tidak berhubungan langsung dengan perilaku kesehatan, yang lebih berpengaruh adalah informasi untuk menambah pengetahuan. ${ }^{8}$
Hasil penelitian ini menunjukkan tidak ada hubungan status pekerjaan responden dengan ketepatan waktu vaksinasi jamaah umrah sejalan dengan penelitian Hafsoh SO ${ }^{7}$ Tetapi penelitian yang dilakukan oleh Abbas KM di Amerika Serikat menunjukkan hasil yang berbeda dimana orang yang tidak bekerja mempunyai proporsi yang lebih besar untuk mendapatkan vaksinasi influenza dibandingkan dengan orang yang tidak bekerja. ${ }^{13}$ Perbedaan hasil penelitian ini disebabkan karena sebagian besar responden yang tidak bekerja adalah ibu rumah tangga, dimana pada saat wawancara mereka adalah jamaah umrah yang berangkat umrah bersama-sama dengan suami atau anaknya yang bekerja, sehingga pada saat melakukan vaksinasi meningitis mereka memilih untuk melakukan vaksinasi berbarengan dengan suami atau anaknya.

\section{Hubungan tingkat pengetahuan dengan ketepatan waktu vaksinasi}

Tidak adanya hubungan antara pengetahuan tentang vaksinasi meningitis dan pengetahuan tentang waktu vaksinasi meningitis berbeda dengan penelitian yang dilakukan oleh Hafsoh SO dimana pengetahuan mempunyai hubungan yang signifikan dengan penerimaan vaksinasi meningitis pada jamaah umrah di Kantor Kesehatan Pelabuhan Kelas 2 Semarang. ${ }^{7}$ Hasil berbeda juga ditemukan pada penelitian Poerwanti $S$ dimana pengetahuan jamaah berhubungan dengan tingkat kepatuhan vaksinasi meningitis. ${ }^{8}$ Perbedaan hasil penelitian ini disebabkan karena penelitian sebelumnya menggabungkan pengetahuan tentang penyakit meningitis, vaksinasi meningitis dan waktu vaksinasi meningitis dalam satu variabel pengetahuan. Sementara pada penelitian ini variabel pengetahuan dibagi menjadi tiga variabel pengetahuan yang mencakup pengetahuan tentang penyakit meningitis, pengetahuan tentang vaksinasi meningitis dan pengetahuan tentang waktu vaksinasi meningitis.

Variabel pengetahuan tentang waktu vaksinasi meningitis menunjukkan adanya hubungan yang signifikan dengan ketepatan waktu vaksinasi meningitis pada jamaah. Hal ini membuktikan bahwa pengetahuan yang spesifik akan lebih memberikan dampak 
terhadap perilaku seseorang dibandingkan dengan pengetahuan yang kurang spesifik. ${ }^{16}$

Informasi yang didapat juga mempengaruhi pengetahuan jamaah tentang waktu vaksinasi meningitis dimana hanya 40,2 $\%$ PPIU yang memberikan informasi tentang waktu vaksinasi yang benar. Sedangkan dari wawancara dengan PPIU didapatkan bahwa PPIU tidak menyampaikan informasi tentang penyakit meningitis dan vaksinasi meningitis.

\section{Dukungan keluarga tidak berhubungan dengan ketepatan waktu vaksinasi}

Salah satu faktor yang mempengaruhi tingkat kepatuhan seseorang terhadap anjuran kesehatan adalah dukungan dari pihak keluarga. Individu merupakan unit terkecil dari keluarga, sehingga keluarga memegang peranan penting dalam membantu individu mematuhi suatu program kesehatan yang harus dijalani. ${ }^{10}$

Namun hasil penelitian menunjukkan tidak ada hubungan antara dukungan keluarga dengan ketepatan waktu vaksinasi pada jamaah umrah serupa dengan penelitian yang dilakukan oleh Hafsoh SO di Kantor Kesehatan Peabuhan Kelas 2 Semarang pada tahun $2018 .^{7}$ Tidak adanya hubungan antara dukungan keluarga dengan ketepatan waktu vaksinasi meningitis pada jamaah umrah ini disebabkan karena waktu vaksinasi responden sebagian besar $(59,0 \%)$ ditetapkan oleh PPIU sehingga responden dan keluarga cenderung menyerahkan semua pengurusan umrah kepada pihak penyelenggara perjalanan ibadah umrah.

\section{Tidak ada hubungan akses jarak dengan ketepatan waktu vaksinasi}

Akses jarak ke pelayanan kesehatan menunjukkan hubungan yang tidak signifikan dengan ketepatan waktu vaksinasi pada jamaah umrah hal ini berbeda dengan hasil penelitian yang dilakukan oleh Supyan A di Kantor Kesehatan Pelabuhan Keals II Semarang. ${ }^{9}$ Salah satu faktor yang dianggap bisa menjadi barrier aksesibilitas pelayanan kesehatan berupa masalah geografis, cakupan luas wilayah, ketersediaan moda transportasi, persebaran dan kepadatan penduduk, sampai dengan ketersediaan pembiayaan kesehatan atau kepemilikan asuransi oleh masyarakat. ${ }^{17}$ tetapi dari pengamatan langsung yang dilakukan peneliti, akses jalan menuju ke Kantor Kesehatan Pelabuhan Bengkulu (tempat vaksinasi meningitis pada jamaah umrah) merupakan jalan dengan status jalan provinsi dimana jalan ini juga merupakan jalan utama dari pusat kota menuju ke bandara Fatmawati Soekarno Bengkulu, sehingga jalan berada dalam kondisi yang sangat baik. Sarana transportasi menuju ke tempat vaksinasi pun terbilang banyak. Terdapat transportasi umum yang melewati KKP berupa angkutan kota dan bus trans bengkulu. Di kota Bengkulu sendiri sudah tersedia ojek online maupun taksi online yang juga memudahkan jamaah dalam transportasi, selain itu kesediaan PPIU menyediakan transportasi bagi jamaah yang membutuhkan juga sangat memudahkan akses ke KKP.

\section{Persepsi terhadap peran PPIU berhubungan dengan ketepatan waktu vaksinasi}

Penelitian ini menunjukkan ada hubungan yang signifikan antara persepsi terhadap peran PPIU dengan ketepatan waktu vaksinasi pada jamaah umrah. Hal ini dikarenakan besarnya peran yang diberikan oleh PPIU dalam pelaksanaan vaksinasi jamaah umrah. Berdasarkan hasil wawancara dengan PPIU didapatkan bahwa 70\% PPIU memberitahukan bahwa jamaah wajib vaksinasi pada saat jamaah mendaftar sehingga dari awal melakukan pendaftaran, jamaah sudah mengetahui tentang kewajiban melakukan vaksinasi meningitis. $70 \% \quad$ PPIU menyampaikan informasi tentang waktu pelaksanaan vaksinasi pada jamaah umrah, sehingga dari awal jamaah sudah memiliki pengetahuan tentang kapan sebaiknya vaksinasi meningitis dilakukan. Tanggal pelaksanaan vaksinasi pun ditentukan oleh PPIU dengan berkoordinasi dengan jamaah jika ada jamaah yang tidak bisa melakukan vaksinasi pada tanggal yang telah ditentukan sehingga ketepatan waktu vaksinasi jamaah lebih bisa terpantau oleh PPIU. Kemudahan pelayanan juga diberikan PPIU dalam bentuk pemberian layanan pendaftaran online $(100 \%)$, sehingga jamaah tidak kesulitan dalam menyiapkan persyaratan yang dibutuhkan untuk vaksinasi karena sudah di siapkan oleh PPIU. PPIU juga 
menyediakan layanan pendampingan jamaah (80\% PPIU selalu mendampingi, 20\% PPIU kadang-kadang mendampingi) pada saat vaksinasi, sehingga jamaah pun tidak kesulitan dalam mengikuti prosedur vaksinasi di Kantor Kesehatan Pelabuhan Bengkulu mulai dari pendaftaran, pemeriksaan maupun pembayaran dimana pembayaran tidak boleh dilakukan secara tunai. Keberadaan tenaga pendamping dari PPIU sangatlah membantu jamaah dalam pelaksanaan vaksinasi meningitis. walaupun secara resmi pihak PPIU tidak menyediakan layanan transportasi bagi jamaah pada saat vaksinasi (100\% PPIU tidak menyediakan transportasi) tetapi kemudahan tetap diberikan PPIU terutama bagi jamaah yang memang membutuhkan transportasi.

\section{Kesimpulan}

Faktor yang sangat mempengaruhi jamaah dalam melakukan vaksinasi tepat waktu adalah pengetahuan tentang waktu vaksinasi yang cukup dan persepsi terhadap peran PPIU yang baik.

\section{Daftar Pustaka}

1. Ibrahim AM, Katiandagho TR. Tatalaksana dan Pencegahan Meningitis Meningokokus. Ikat Dr Indones [Internet]. 2018 [cited 2019 Jan 9];45:30-4. Available from: http://www.kalbemed.com/Portals/6/09_E disi suplemen-1 18_Tatalaksana dan Pencegahan Meningitis Meningokokus.pdf

2. Memish ZA. Meningococcal Disease and Travel. 2002;34. Available from: https://www.ncbi.nlm.nih.gov

3. Ghany MA El, Sharaf H, Hill-cawthorne GA. International Journal of Infectious Diseases Hajj vaccinations: facts, challenges, and hope. Int $\mathrm{J}$ Infect Dis [Internet]. 2016;47:29-37. Available from: http://dx.doi.org/10.1016/j.ijid.2016.05.02 4

4. Siegrist C. Vaccine Immunology. In: Vaccine Immunology. 2008. p. p.1-26.
5. Kementerian Kesehatan Republik Indonesia. PMK No 12 Tahun 2017 Tentang Penyelenggaraan Imunisasi. Kementerian Kesehatan Republik Indonesia; 2017.

6. Sevin AM, Romeo C, Gagne B, Brown N V, Rodis JL. Factors influencing adults' immunization practices: a pilot survey study of a diverse, urban community in central Ohio. BMC Public Health. 2016;16(424):2-8.

7. Hafshoh SO, Musthofa SB, Husodo BT. Beberapa Faktor Yang Berhubungan Dengan Penerimaan Jamaah Umrah Terhadap Vaksin Meningitis Di Kantor Kesehatan Pelabuhan Kelas II Semarang. J Kesehat Masy [Internet]. 2019;7(1):52734. Available from: http://ejournal3.undip.ac.id/index.php/jkm $\% 25$

8. Poerwanti S, Sulisetyawati D, Priambodo G. Hubungan Pengetahuan dan Sikap Jemaah Umroh dengan Kepatuhan Vaksinasi Meningitis di Kantor Kesehatan Pelabuhan Semarang Wilayah Kerja Bandara Adisumarno. 2015.

9. Supyan A. Faktor-faktor Yang Berhubungan Dengan Praktik Vaksinasi Meningitis Oleh Jamaah Umrah di Kantor Kesehtan Pelabuhan Kelas II Semarang Tahun 2016. Universitas Dian Nuswantoro; 2016.

10. Niman S. Promosi dan Pendidikan Kesehatan. 1st ed. Taufik Ismail, editor. Jakarta: Trans Info Media; 2017. 141 p.

11. Notoatmodjo S. Promosi Kesehatan dan Perilaku Kesehatan. Revisi 201. Jakarta: PT. Rineka Cipta; 2012. p. 250.

12. Yulia S. Faktor-faktor yang mempengaruhi kepatuhan dalam menjalankan diet pada penderita diabetes mellitus tipe 2. Kesehat Masy. 2015;2(dm):1-187. 
13. Abbas KM, Kang GJ, Chen D, Werre SR, Marathe A. Demographics, perceptions, and socioeconomic factors affecting influenza vaccination among adults in the United States. Peer J [Internet]. 2018 [cited 2019 Aug 29];15. Available from: https://peerj.com/articles/5171/

14. Yulia S. Faktor-faktor yang mempengaruhi kepatuhan dalam menjalankan diet pada penderita Diabetes Mellitus tipe 2 (Studi kasus di Puskesmas Kedungmundu Tahun 2015). Universitas Negeri Semarang; 2015.

15. Egici MT, Tas BG, Ozkarafakıl1 MA, Ozturk GZ. Evaluation of Factors Affecting Adult Immunization. Haydarpasa Numune Med J [Internet]. 2018 [cited 2019 Aug 26];58(3):128-32. Available from: https://www.journalagent.com/hnhjournal/ pdfs/HNHJ_58_3_128_132.pdf\#targetText =Adult vaccination is grouped by,- migrant vaccination $\% 5 \mathrm{~B} 13 \% 5 \mathrm{D}$.
16. Subaris H. Promosi Kesehatan, Pemberdayaan Masyarakat Dan Modal Sosial. Pertama. Yogyakarta: Nuha Medika; 2016. 150 p.

17. Laksono AD, Sukoco NE. Studi Kasus Aksesibilitas Pelayanan Kesehatan di Kabupaten Maluku Tenggara Barat. In: Aksesibilitas Pelayanan Kesehatan di Indonesia [Internet]. 2009. p. 85-107. Available from: https://www.academia.edu/37061121/Studi _Kasus_Aksesibilitas_Yankes_di_MTB 